\title{
O PLANO DIRETOR COMO INSTRUMENTO DE CONCREÇÃO DO ESTADO SOCIOAMBIENTAL DE DIREITO ANTE A FUNÇÃO SOCIAL E AMBIENTAL DA PROPRIEDADE
}

\author{
THE DIRECTOR PLAN AS AN INSTRUMENT FOR THE CONCRETION OF THE SOCIAL AND \\ ENVIRONMENTAL STATE OF RIGHT TO THE SOCIAL AND ENVIRONMENTAL FUNCTION OF THE \\ PROPERTY
}

\section{Lucas de Souza Lehfeld ${ }^{1}$ Juliana Castro Torres ${ }^{2}$}

\section{RESUMO}

O artigo objetiva demonstrar como o Plano Diretor pode ser capaz de garantir o Estado Socioambiental de Direito, que tem a sustentabilidade com base na tutela de direitos sociais, econômicos e ambientais, visando uma política pública urbana que assegure o desenvolvimento sustentável das cidades e o uso adequado do solo, respeitando as funções socioambientais e garantindo a dignidade dos seus habitantes. O Plano Diretor orienta para que haja a implantação mais equitativa de um padrão de vida urbano, com equipamentos de saúde, educação, segurança, saneamento, mobilidade urbana e moradia digna, buscando promover à população um ambiente ecologicamente equilibrado e organizado, para que todos tenham condições dignas de sobrevivência, convertendo para a concreção desta sustentabilidade. Porém, o que se observa é a falta de controle sobre o uso e a ocupação do solo, gerando grandes desafios no processo de urbanização. O estudo destaca o Plano Diretor como um instrumento público eficaz e capaz de combater estes problemas e garantir a ideal organização das

\footnotetext{
${ }^{1}$ Possui graduação em Direito pela Universidade de Ribeirão Preto (1999), graduação em Ciências Contábeis pela Universidade de São Paulo (1999), mestrado em Direito das Obrigações pela Universidade Estadual Paulista Júlio de Mesquita Filho (2001) e doutorado em Direito pela Pontifícia Universidade Católica de São Paulo (2006). PósDoutor em Direito pela Universidade de Coimbra (POR). Atualmente é docente titular da Universidade de Ribeirão Preto (Graduação e Pós-Graduação Stricto Sensu em Direito (mestrado) e Tecnologia Ambiental (mestrado e doutorado)), Coordenador do Curso de Direito do Centro Universitário Barão de Mauá (graduação e pós-graduação EAD) e docente do Centro Universitário da Fundação Educacional de Barretos. Avaliador de cursos de direito pelo Ministério da Educação (INEP) e Conselho Estadual de Educação do Governo do Estado de São Paulo (CEE). Universidade de Ribeirão Preto - UNAERP - Brasil. ORCID: http://orcid.org/0000-0002-10210891 Lattes: http://lattes.cnpq.br/4048647397200408 E-mail: lehfeldrp@gmail.com

2 Professora da Universidade do Estado de Minas Gerais - Unidade Passos. Mestranda em Direitos Coletivos e Cidadania na Universidade de Ribeirão Preto - UNAERP. Universidade do Estado de Minas Gerais - UEMG. Brasil. ORCID: http://orcid.org/0000-0001-9094-4715 Lattes: http://lattes.cnpq.br/4486423547641606 E-mail: jucastrotorres@hotmail.com
} 
cidades, contando com a participação democrática da população nos seus processos de construção e atualização, através dos mecanismos de gestão democrática afirmados no Estatuto da Cidade. A pesquisa se caracteriza como sendo teórica e bibliográfica e o método de procedimento é o dedutivo, valendo-se de material histórico, sociológico e jurídico, a partir de livros e artigos científicos.

Palavras-chave: Plano Diretor. Socioambiental. Propriedades. Sustentabilidade. Dignidade.

\section{ABSTRACT}

The article aims to demonstrate how the Master Plan can be able to guarantee the SocioEnvironmental Rule of Law, which has sustainability based on the protection of social, economic and environmental rights, aiming at an urban public policy that ensures the sustainable development of cities and the use soil, respecting socio-environmental functions and guaranteeing the dignity of its inhabitants. The Master Plan guides the implementation of a more equitable standard of urban living, with equipment for health, education, security, sanitation, urban mobility and decent housing, seeking to promote to the population an ecologically balanced and organized environment, so that everyone has decent conditions for survival, converting to the concretization of this sustainability. However, what is observed is the lack of control over land use and occupation, creating major challenges in the urbanization process. The study highlights the Master Plan as an effective public instrument capable of combating these problems and guaranteeing the ideal organization of cities, counting on the democratic participation of the population in its processes of construction and updating, through the mechanisms of democratic management stated in the Statute of the City. The research is characterized as being theoretical and bibliographic and the method of procedure is the deductive one, making use of historical, sociological and legal material, from books and scientific articles.

Keywords: Master plan. Socio-environmental. Properties. Sustainability. Dignity.

\section{INTRODUÇÃO}

O crescimento acelerado das populações nos centros urbanos fez com que ocorresse uma ocupação inadequada do solo, gerando uma crise urbana ou hiperurbanização, caracterizada pelo mau uso dos recursos naturais e pelo aumento da desigualdade social, onde parte da população se desenvolveu física, econômica e socialmente, e outra, cresceu em condições mínimas de sobrevivência, em desatenção as necessidades básicas para a vida com dignidade. 
A falta de controle sobre o uso e a ocupação do solo vem acarretando inúmeras consequências além das sociais também ambientais, como inundações e desmoronamentos, geralmente, atingindo a população de baixa renda, que normalmente é alocada nas periferias das cidades, em áreas carentes de infraestrutura.

Para contornar a situação de desigualdade estabeleceram-se normas de planejamento urbano sustentável, destacando-se o Plano Diretor como uma política pública de concretização da função social da cidade e da propriedade, que trata do direito à terra urbana, da moradia, do saneamento ambiental, da infraestrutura urbana, do transporte e serviço público, do trabalho, do lazer, sem contar o direito à cidade como um direito coletivo.

Sendo assim, o presente artigo vem demonstrar como o Plano Diretor pode ser um instrumento seguro e eficaz para a garantia do Estado Socioambiental de Direito, assegurando a tutela de direitos sociais, econômicos e ambientais, dispondo para que haja a implantação mais equitativa de um padrão de vida urbano, com equipamentos de saúde, educação, segurança, saneamento, mobilidade urbana e moradia digna, pautados nos anseios da população.

O tema é de interesse de toda a coletividade, considerando o instituto como instrumento eficiente de promoção da função socioambiental da propriedade e da cidade, promovendo o meio ambiente equilibrado e dignidade aos habitantes.

O Plano Diretor está previsto na Constituição Federal de 1.988 e na Lei 10.257/01 que instituiu o Estatuto da Cidade, sendo instrumento obrigatório para cidades com mais de 20.000,00 (vinte mil) habitantes que tem como principal objetivo a promoção do desenvolvimento sustentável das cidades, orientando a atuação do poder público e a iniciativa privada na construção dos espaços urbano e rural, visando assegurar melhores condições de vida para a coletividade da população.

Para tanto, a pesquisa foi desenvolvida a partir de pesquisa bibliográfica, nas áreas de direito constitucional, ambiental- urbanístico e administrativo, onde se buscou compreender o que é o Estado Socioambiental de Direito e como o Plano Diretor pode ajudar na concretização deste instituto, como a boa organização das cidades podem proporcionar à sua população uma vida digna, um meio ambiente equilibrado.

Assim, organizou-se um estudo sobre o processo de urbanização e as razões do planejamento urbano, elencando como base os princípios da função social e socioambiental da propriedade e o direito ao meio ambiente equilibrado, passando-se em seguida à análise do Plano Diretor como instrumento eficaz para a concreção do Estado Socioambiental de Direito, capaz de assegurar o 
desenvolvimento sustentável, com atendimento das necessidades dos cidadãos quanto à qualidade de vida, à justiça social e ao desenvolvimento das atividades econômicas.

Ao final, utilizando-se do método dedutivo, concluiu-se que o Plano Diretor devidamente implementado se torna um importante instrumento de concreção da cidadania e democracia, possibilitando a participação da população na formulação de políticas públicas no intuito de planejar e ordenar o solo urbano, evitando ou abrandando problemas como favelização, empobrecimento de parcela da população, miséria e delinquência, decorrentes da má-distribuição de renda, da especulação imobiliária e da ausência de reforma agrária.

\section{O PROCESSO DE URBANIZAÇÃO E AS RAZÕES DO PLANEJAMENTO URBANO}

O processo de urbanização no Brasil se deu de modo acelerado, gerando um crescimento desordenado das metrópoles, em razão do desequilíbrio e desintegração da política regional e nacional.

Segundo a Política Nacional de Desenvolvimento Urbano - PNDU (MINISTÉRIO DAS CIDADES, 2004, p. 29), cerca de $80 \%$ da população do país mora em área urbana e, em escala variável, as cidades brasileiras apresentam problemas comuns que foram agravados, ao longo dos anos pela falta de planejamento, reforma fundiária, controle sobre o uso e a ocupação do solo. A PNDU adota uma tese central de que vivemos uma Crise Urbana que exige uma política nacional orientadora e coordenadora de esforços, planos, ações e investimentos dos vários níveis de governo, e também, dos legislativos, do judiciário, do setor privado e da sociedade civil. O que se busca é a equidade social, maior eficiência administrativa, ampliação da cidadania, sustentabilidade ambiental e resposta aos direitos das populações vulneráveis: crianças e adolescentes, idosos, pessoas com deficiência, mulheres, negros e índios. A Crise Urbana se instaura e se espraia por influência de mudanças no contexto internacional, a derrocada do socialismo real, a financeirização da economia, o crescimento explosivo da dívida externa, a revolução tecnológica, a chamada reestruturação produtiva e os novos modos de gestão e regulação do trabalho, com sua esteira de precarização do emprego e ampliação das desigualdades.

Importante perceber o quão atual é esse estudo da PNDU, haja vista que estas situações ainda estão presentes na sociedade contemporânea, inclusive com vistas a um profundo agravamento pela situação de desenvolvimento do país. 
Segundo Castells:

A urbanização latino-americana caracteriza-se então pelos traços seguintes: população urbana sem medida comum com o nível produtivo do sistema; ausência de relação direta entre emprego industrial e crescimento urbano; grande desequilíbrio na rede urbana em benefício de um aglomerado preponderante; aceleração crescente do processo de urbanização; falta de empregos e de serviços para as novas massas urbanas e, consequentemente, reforço da segregação ecológica das classes sociais e polarização do sistema de estratificação no que diz respeito ao consumo (CASTELLS, 1983, p. 99).

As diretrizes gerais da política urbana estão dispostas no Capítulo I do Estatuto da Cidade (BRASIL, 2001) destacando-se a garantia do direito às cidades sustentáveis, no sentido de exercitar plenamente a cidadania e os direitos humanos (direitos políticos, civis, econômicos, culturais, sociais e ambientais); a gestão democrática da cidade, que é a base para o desenvolvimento sustentável das cidades, devido aos preceitos constitucionais da democracia participativa, da cidadania, da soberania e participação popular; a ordenação e controle do uso do solo visando evitar a retenção especulativa de imóvel urbano, levando-se em consideração as reais condições das diferentes partes da cidade e a ocupação adequada que elas podem receber; a regularização fundiária e a urbanização de áreas ocupadas por população de baixa renda, tratando de uma necessária proteção ao direito de moradia à população, evitando problemas profundos de desigualdades sociais como por exemplo o favelamento.

Para Norberto Bobbio (1992, p.68) as mudanças no tecido social implicam no nascimento de novos direitos, o que faz com que o quadro geral normativo, apoiado em tradicionais categorias jurídico-normativas, se amplie, para atender não apenas a fatores econômicos, expresso pelo aumento da tutela de bens, antes excluídos de proteção, mas particularmente para compreender o homem não como um ser abstrato.

Desta feita, nasceu o Direito Urbanístico, um ramo do Direito Público criado com a finalidade de disciplinar os espaços habitáveis pelo homem, sejam eles urbanos ou rurais, preocupado em atender as necessidades de habitação, trabalho, lazer e circulação na comunidade, ou seja, atendendo à função social da propriedade.

A urbanização é cada vez mais uma tendência da sociedade moderna, caracterizada pela busca do bem estar da coletividade, em atenção para as necessidades do gênero. É a forma encontrada de ordenar o crescimento da cidade, utilizando-se de normas que promovam o adequado parcelamento do solo e que atendam principalmente as funções sociais necessárias para o seu bom funcionamento. 
Toshio Mukai (2002, p. 16) considera que "o urbanismo é concebido em termos funcionais e racionais, com uma preocupação básica humana, isto é, com valores espirituais, visando o homem no contexto urbano e a melhoria das suas condições de vida".

Outrora conclui Baltar (1957) apud Hely Lopes Meirelles que:

Urbanismo é, em suma, uma ciência, uma técnica e uma arte, ao mesmo tempo, onde o objetivo é organizar o espaço urbano atentando ao bem - estar coletivo, utilizando-se de uma legislação, de um planejamento e da execução de obras públicas que permitam o desempenho harmônico e progressivo das funções urbanas elementares, que são: habitação, trabalho, recreação e circulação no espaço urbano (MEIRELLES, 2008, p. 522).

Na mesma linha de pensamento, Meirelles (2008, p. 525) conceitua o Direito Urbanístico como sendo o "ramo do Direito Público destinado ao estudo e formulação dos princípios e normas que devem reger os espaços habitáveis, no seu conjunto cidade - campo".

Já para Georges Louis Hage Humbert, a concepção de Direito Urbanístico apresentada por Hely Lopes Meirelles não supre a necessidade da sociedade, devendo ser importante frisar que:

O Direito Urbanístico tem como objeto o estudo das normas - regras e princípios - que visam ordenar as cidades. Dedica importante atenção e concentra especiais esforços aos direitos e limitações inerentes à propriedade urbana, sua regulação e organização, indispensável diante do premente fenômeno da concentração urbana iniciado a partir das revoluções burguesas e industriais ocorridas na Europa Ocidental e logo refletidas no Brasil. Surge, então, como disciplina indispensável para consecução de uma urbe que permita aos citadinos uma vida saudável e feliz (HUMBERT, 2006, p. 1).

Portanto, podemos conceituar o Direito Urbanístico como sendo um conjunto de normas que finalizam a organização do solo buscando proporcionar melhores condições de vida às pessoas. Este instituto interpreta e sistematiza as normas e os princípios que disciplinam o espaço urbano e é, portanto, peça fundamental dentro das cidades, visando uma melhor organização dos espaços habitáveis, protegendo o ambiente em prol da sociedade, buscando atender a função social da propriedade, e os demais princípios atinentes ao bem-estar coletivo.

Hely Lopes Meirelles ainda afirma que este direito aponta as diretrizes básicas para se alcançar um planejamento urbano adequado:

O conjunto de medidas estatais destinadas a organizar os espaços habitáveis, de modo a propiciar melhores condições de vida ao homem na comunidade. Entenda-se por espaços habitáveis todas as áreas em que o homem exerce 
coletivamente qualquer das quatro funções sociais: habitação, trabalho, circulação, recreação. (MEIRELLES, 2008, p. 522)

Contudo, notadamente é a necessidade de ordenação das cidades para que perpetuem estes direitos aos cidadãos, pois, afinal conforme explica Maciel e Schorr a cidade:

É uma forma de organizar o território e a relação política entre os que nela habitam.

$[\ldots]$

A cidade pode ser considerada uma obra coletiva que acaba por desafiar a natureza, uma vez que o homem sempre a explorou, retirando dela o necessário para sua sobrevivência. Um aglomerado de pessoas que se estabelecem em um local, e que participam da vida pública, mesmo que isto represente apenas submeter-se às regras e aos regulamentos (MACIEL; SCHORR, 2015, p. 153).

O Estatuto da Cidade previsto pela Lei 10.257/01 atribuiu competência à Lei municipal para demandar sobre o parcelamento do solo, dispondo em seu artigo 5으, caput, que:

Art. 5․ Lei municipal específica para área incluída no plano diretor poderá determinar o parcelamento, a edificação ou utilização compulsórios do solo urbano não edificado, subutilizado ou não utilizado, devendo fixar as condições e os prazos para implementação da referida obrigação.

A lei de parcelamento do solo orienta o projeto e a execução de qualquer obra dentro do município, assegurando as normas de urbanização para que sejam respeitados os interesses coletivos e os direitos fundamentais do ser humano.

Para atender a função socioambiental, a cidade deve ser dividida em zonas de acordo com a finalidade de seu uso e ocupação e Hely Lopes Meirelles citando a Carta dos Andes (1960) conceitua o zoneamento urbano:

O instrumento legal de que dispõem as Municipalidades para controlar o uso do solo povoado, as densidades de população, a localização, a dimensão, o volume dos edifícios e suas utilizações específicas, em prol do bem-estar da comunidade (MEIRELLES, 2006, p. 564).

As zonas industriais por serem destinadas à instalação de fábricas e atividades industriais, devem estar situadas em locais próprios, escolhidos para a sua instalação, longe dos bairros residenciais, pois produzem barulho, causam desconforto aos vizinhos, prejudicam a qualidade de vida dos habitantes (MUKAI, 2004). 
Meirelles (2008, p.565) também explana que "a divisão da cidade em zonas delega a cada setor um uso específico de acordo com seu destino, como por exemplo, as indústrias, que devem ser instaladas em locais isolados, longe das residências".

Nesta esteira, podemos concluir que o Planejamento Urbano visa à organização das regiões habilitadas a receber a ação do homem, buscando melhorar as necessidades da população da área, visando o bem-estar comum, no sentido de obter lazer, habitação, trabalho e circulação na comunidade, obedecendo aos princípios da função socioambiental da propriedade, legalidade, hierarquia, e igualdade.

Assim é regido o Estado Socioambiental de Direito conceituado por Ingo Wolfgang Sarlet e Tiago Fensterseifer:

Configura-se em um marco jurídico-constitucional ajustado à necessidade da tutela e promoção, de maneira integrada e independente, dos direitos sociais e dos direitos ambientais num mesmo projeto jurídico-político para o desenvolvimento humano em padrões sustentáveis, inclusive pela perspectiva da noção ampliada e integrada dos direitos fundamentais socioambientais ou direitos fundamentais econômicos, sociais, culturais e ambientais (SARLET; FENSTERSEIFER, 2012, p. 45).

Os Autores Lehfeld e Oliveira (2016, p. 280) concluem acerca deste conceito que "a finalidade do Estado Socioambiental de Direito, portanto, é a sustentabilidade, com base na tutela de direitos sociais, econômicos e ambientais" e ainda, que a sustentabilidade qualifica ou caracteriza o desenvolvimento no Estado Socioambiental de Direito.

Destarte, para que uma área urbana ou rural seja habitável, atendendo as necessidades da população, deve ser sustentável, deve-se planejar todo o local, ou seja, observar a natureza da ocupação e sua finalidade, estudar a geografia local atentando para a questão ambiental, buscando boas condições de vida para as pessoas que habitarão o local, unificando os interesses da coletividade com os dos particulares, visando o desenvolvimento econômico e social.

Sendo assim, o Direito Urbanístico surge como forma de coação, sendo parte fundamental para a eficácia do planejamento urbano, atribuindo ao Poder Público a função de intervir dentro da área urbana para delimitar restrições em atenção ao bem comum.

Referidas restrições devem se estender a todos e a tudo a fim de garantir o bem maior que é a coletividade, devendo, portanto, a atuação urbanística ter uma imposição legal (MEIRELLES, 2006). 
Contudo, é, portanto, notável e imprescindível a promoção do planejamento urbano para melhoria da vida em sociedade, tornando-se o objeto precípuo do Direito Urbanístico na busca da concreção do Estado Socioambiental de Direito.

Ademais, importante observar alguns princípios que limitam o uso do solo, regendo o direito de propriedade, para que os direitos fundamentais do cidadão não sejam violados, para o que bem estar individual não ultrapasse o bem estar da coletividade, pelo que se passa ao estudo dos princípios da função social e socioambiental da propriedade e sua relação para o meio ambiente equilibrado.

\section{A FUNÇÃO SOCIAL DA PROPRIEDADE E O MEIO AMBIENTE EQUILIBRADO}

A propriedade é um direito natural do homem, essencial para a sua sobrevivência, desenvolvimento e autonomia, mas deve seguir limitações para que ela seja um bem em conformidade com os princípios da função social e socioambiental da propriedade, fundada no bem comum, em um ambiente equilibrado e sustentável.

Maria Helena Diniz conceitua a propriedade como sendo "o direito que a pessoa física ou jurídica tem, dentro dos limites normativos, de usar, gozar e dispor de um bem corpóreo, bem como de reivindicar de quem injustamente o detenha" (DINIZ, 2009, p. 847).

Nesse sentido, Carlos Alberto Gonçalves (2017, p. 242) define o direito de propriedade como "o poder jurídico atribuído a uma pessoa de usar, gozar e dispor de um bem, corpóreo ou incorpóreo, em sua plenitude e dentro dos limites estabelecidos na lei, bem como de reivindicá-lo de quem injustamente o detenha".

Este direito ainda é assegurado pela Constituição Federal dispondo em seu artigo 5ㅇ, XXII e XXIII que "é garantido o direito de propriedade" e que "a propriedade atenderá a sua função social", explicitando que ela deve atender ao interesse coletivo unificado com os interesses privados.

Importante destacar que os incisos supra citados orientam o Título VII, Capítulo II, Art. 170, da Ordem Econômica e Financeira do mesmo instituto, prescrevendo que a ordem econômica fundada na valorização do trabalho humano e na livre iniciativa, visa garantir a todos, condições de existência digna, atendendo princípios como o da propriedade privada e o da função social da propriedade.

O Código Civil também garante este direito, mencionando-o em seu artigo 1.288 caput que "o proprietário tem a faculdade de usar, gozar e dispor da coisa, e o direito de reavê-la do poder de quem quer que injustamente a possua ou detenha." 
Os princípios da função social da cidade e da propriedade urbana são resultados do Movimento Nacional para a Reforma Urbana que propunha a sua aplicação imediata em todas as áreas urbanas.

Com a promulgação da Carta Maior, as funções sociais da cidade e da propriedade urbana foram tratadas no capítulo da Política Urbana, nos artigos 182 (1) e 183 (2), apontando que o desenvolvimento urbano deve promovê-las por meio do Plano Diretor Municipal.

Assim, a deliberação foi de que estas funções deveriam ser estabelecidas pelos Planos Diretores Municipais e, portanto a sua relevância para o Estado Socioambiental de Direito, eis que estes são instrumentos que propõem limites para que as propriedades e a cidade cumpram as suas funções em observância ao meio ambiente equilibrado e sustentável.

Em uma visão ampliada, Lehfeld e Oliveira (2016, p. 287) ressaltam que a propriedade como direito fundamental tem como condição sine qua non para o seu exercício, não só o cumprimento de sua função social, mas também ambiental.

Esta disposição implica que o direito de propriedade seja exercido também atendendo à função social da cidade, ou seja, seu uso deverá ser efetivamente compatível com a destinação socioeconômica do bem e sua utilização deverá respeitar o meio ambiente, as relações de trabalho, o bem-estar social e a utilidade de exploração, a fim de se manter o ambiente equilibrado, garantindose a dignidade da pessoa humana e a liberdade individual.

Desta forma, os Planos Diretores Municipais têm um papel fundamental para que a cidade atinja os seus objetivos e anseios, para que a sociedade consiga viver em um ambiente equilibrado e com dignidade, impondo limitações quanto ao uso do solo em prol de todos.

O planejamento urbano nas palavras de Nascimento $(2006$, p. 8) "confere máxima proteção legal ao meio ambiente ecologicamente equilibrado, e seus fundamentos ligam-se à proteção da vida e da saúde, salvaguardando a dignidade da pessoa humana e visando a funcionalização ecológica da vida social".

Assim, o proprietário, no uso de suas atribuições poderá usar, gozar, dispor e reaver da sua propriedade, desde que atenda a sua função social e ambiental, o que deve ser previsto no Plano Diretor do Município e, detectando a Administração, indícios de infringência sobre esse princípio, poderá o Estado intervir sobre a atuação do correspondente infrator.

A cidade, para Coelho e Oliveira $(2018$, p.14) é a forma mais completa de comunidade, onde o ser humano encontra todas as condições para o desenvolvimento de suas potencialidades e para a satisfação de suas necessidades. 
Maciel e Schorr definem as cidades como sendo:

Espaços sociais que devem oferecer aos seus habitantes condições e oportunidades equitativas, a fim de que possam viver com dignidade independentemente de suas características, sociais, éticas e culturais, possibilitando que os habitantes se apropriem e usufruam de forma igual da riqueza que as cidades pode lhes proporcionar, tanto no aspecto econômico, quanto na produção de conhecimento e cultura (MACIEL; SCHORR, 2015, p. 159).

Assim, para que a cidade atenda a sua finalidade é necessário que ela siga algumas diretrizes, algumas limitações a fim de garantir a vida digna aos seus moradores, um ambiente equilibrado e, nesse sentido, a Política Nacional de Desenvolvimento Urbano, na 1aㅡ Conferência das Cidades, definiu as funções sociais da cidade e da propriedade:

A propriedade urbana e a cidade devem cumprir sua função social, entendida como a prevalência do interesse comum sobre o direito individual de propriedade, contemplando aspectos sociais, ambientais, econômicos (de inclusão social) e a implantação combinada com os instrumentos do Estatuto da Cidade (Ministério das Cidades 2004, p. 77).

Importante destacar também os termos do artigo 39, caput e $\S 20$ da Lei $10.257 / 01$, que dispõe:

Art. 39. A propriedade urbana cumpre sua função social quando atende as exigências fundamentais de ordenação da cidade expressas no plano diretor, assegurando $o$ atendimento das necessidades dos cidadãos quanto à qualidade de vida, à justiça social e ao desenvolvimento das atividades econômicas, respeitadas as diretrizes previstas no art. 20 desta Lei.

(...)

$\S 2$, A política urbana tem por objetivo ordenar o pleno desenvolvimento das funções sociais da cidade e da propriedade urbana, mediante as seguintes diretrizes gerais: (...).

Assim, pode-se perceber que "a propriedade não é um direito subjetivo do proprietário, mas a função social do detentor da riqueza. Assim sendo, deve ele gerir a coisa, tendo em vista o seu melhor rendimento e no interesse de todos" (HARADA, 2006, p. 5).

Outrossim, o princípio da função social da propriedade é uma norma que não dispõe de força coercitiva para ser atendida, utilizando-se o Poder Público do poder de polícia para efetuar a fiscalização urbanística. O descumprimento da função socioambiental é uma violação da norma maior, ou seja, de um princípio constitucional.

A função social da propriedade é princípio essencial do Direito Urbanístico, necessário para a concretização de um planejamento urbano ideal, que garanta o bem-estar comum, preocupado com 
todas as questões pertinentes ao uso correto do solo, garantindo a dignidade humana e a liberdade individual. Este princípio é o objetivo principal buscado pela política de desenvolvimento urbano, extraído do artigo 182 da Constituição Federal.

O princípio da função social da propriedade é voltado à consecução da finalidade última de toda ordem jurídica democrática, qual seja, a valorização da dignidade humana, que no plano da normativa ambiental é alcançada por regras que propiciem a vida com saúde e um meio ambiente natural e cultural que permita o desenvolvimento das potencialidades criativas do ser humano (TÓRTOLA, 2012, p. 153).

A Constituição Federal de 1988 garante o direito de propriedade condicionando-o ao atendimento da função social, determinando ainda, sanções, caso haja descumprimento deste princípio, assim dispondo em seu artigo 182, § 4으:

$\S 4$ ํ É facultado ao Poder Público municipal, mediante lei específica para área incluída no plano diretor, exigir, nos termos da lei federal, do proprietário do solo urbano não edificado, subutilizado ou não utilizado, que promova seu adequado aproveitamento, sob pena, sucessivamente, de:

I - parcelamento ou edificação compulsórios;

II - imposto sobre a propriedade predial e territorial urbana progressivo no tempo;

III - desapropriação com pagamento mediante títulos da dívida pública de emissão previamente aprovada pelo Senado Federal, com prazo de resgate de até dez anos, em parcelas anuais, iguais e sucessivas, assegurados o valor real da indenização e os juros legais.

Com efeito, a promoção do planejamento urbano para promover um ambiente equilibrado na cidade, deve observar os princípios urbanísticos quanto ao direito de propriedade, a cidade deve exercer a sua função social e ambiental, avaliando-se a área a ser utilizada, os benefícios que proverão dela para a comunidade a ser instalada, e as consequências para o meio ambiente que surgirão com a futura habitação.

\subsection{Do meio ambiente como direito fundamental}

O meio ambiente equilibrado é uma garantia constitucional, prevista no artigo 225 da Constituição Federal em que:

Todos têm direito ao meio ambiente ecologicamente equilibrado, bem de uso comum do povo e essencial à sadia qualidade de vida, impondo-se ao Poder Público e à coletividade o dever de defendê-lo e preservá-lo para as presentes e futuras gerações. 
Hodiernamente, o tema mais preocupante é o meio ambiente com o aquecimento global, as consequências que a globalização e falta de planejamento tem resultado para o mundo. Observa-se que a consciência humana é o maior precursor deste problema, pois usa de sua força e egoísmo para buscar a melhor condição de vida para si mesmo, esquecendo-se do coletivo. O maior problema da humanidade é a ambição, a falta de preocupação, de conscientização e interesse em preservar o meio ambiente, quem dispõe de uma fonte, não quer saber se ela é renovável ou não, quer explorá-la até a última gota, retirar dela o maior lucro possível, e só então, depois de quase esgotada, é que se preocupa com as consequências, e mesmo assim, visando apenas à continuidade da exploração.

Outro fator gerador do desastre ambiental, juntamente ao egoísmo e à ambição é a falta de planejamento urbano. Antigamente, as cidades simplesmente cresciam, sem a menor preocupação com o resto da população e com o ambiente. A preocupação com o desenvolvimento da cidade fez com que a industrialização ampliasse rapidamente, crescendo desordenadamente, sem a preocupação com a função social da propriedade ou o meio ambiente, buscando apenas o bem-estar empresarial e produtivo para o desenvolvimento da área.

Segundo Mukai:

[...] há uma natural necessidade de refletirmos sobre a posição do homem em face da natureza e demais ambientes que o circundam, em termos filosóficos. Não se pode admitir, atualmente, que o homem se posicione como mero explorador das riquezas naturais colocadas à sua disposição. $O$ entendimento mais aceito é de que o homem é apenas mais um dos elementos do meio ambiente, que, como os demais, interagem entre si, e que os recursos naturais passíveis de exploração são escassos, devendo ser corretamente utilizados, de forma a alterar o menos possível o equilíbrio natural (MUKAI, 2007, p. 165-166).

O meio ambiente é tutelado pelo Direito Ambiental, possuindo normas específicas de controle, fiscalização, sistematização e preservação, dispondo também, de órgãos especializados, capazes de promover estas normas. O Direito Ambiental é objeto do Direito Urbanístico e de interesse do homem que instala, cria e retira de dentro dele as necessárias fontes para a sua sobrevivência.

Hely Lopes Meirelles aponta que:

A proteção ambiental visa à preservação da Natureza em todos os elementos essenciais à vida humana e à manutenção do equilíbrio ecológico, diante do ímpeto predatório das nações civilizadas, que, em nome do desenvolvimento, devastam florestas, exaurem o solo, exterminam a fauna, poluem as águas e o ar (MEIRELLES, 2008, p. 579). 
Com o crescimento das cidades, a civilização começa a avaliar a necessidade de proteger o meio ambiente, preocupando com a sobrevivência das futuras gerações. Há alguns anos atrás, esta preocupação começava a ser divulgada, mas não atingiu nenhum êxito, sendo muitas vezes motivo de chacota. Nos dias atuais a população vem sofrendo as consequências do impacto ambiental, e por isso, vários países iniciaram um processo de conscientização promovendo vários projetos contra a degradação do meio ambiente.

A Lei 6.938/81 (BRASIL, 1981), que expõe sobre a proteção ao meio ambiente, instituiu a Política Nacional do Meio Ambiente e criou o respectivo Sistema Nacional de Preservação e Controle (SISNAMA), que é composto por órgãos da União, dos Estados e dos Municípios e é responsável por apurar a infração administrativa ambiental, que para Meirelles (2008, p. 592) é "toda ação ou omissão às regras jurídicas de uso, gozo, promoção, proteção e recuperação do meio ambiente".

A referida lei atribuiu ao Ministério do Meio Ambiente, órgão central da Administração Ambiental, a função de planejar e supervisionar a Política Nacional do Meio Ambiente, e ao IBAMA (Instituto Brasileiro do Meio Ambiente e dos Recursos Naturais Renováveis) a função de executar essa Política.

A Política Nacional do Meio Ambiente busca unir a preservação da qualidade do meio ambiente e do equilíbrio ecológico com o desenvolvimento econômico-social.

A proteção ao meio ambiente é de competência comum da União, dos Estados, do Distrito federal e dos Municípios, dividindo-se através do artigo $24, \mathrm{VI}$, e $\S \S 10$ e 20 , da CF expondo que as normas gerais serão de competência da União, a legislação supletiva do Estado-Membro e o provimento dos assuntos locais do Município.

De acordo com Meirelles (2008, p. 581), a ação do Município é limitada ao seu território, mas se estende a tudo que afete seus habitantes, promovendo o controle da poluição, preservação dos recursos naturais e restauração dos elementos destruídos, no âmbito da proteção ambiental.

Um instituto utilizado para promover a proteção ambiental é a ação civil pública, capaz de recuperar elementos destruídos ou reparar danos causados ao meio ambiente, proteger os interesses difusos e coletivos da coletividade, é instituída pela Lei no 7.347/85. Quem tem legitimidade para propô-la é o Ministério Público expresso no artigo 129, III, da CF/88:

Art. 129, III, São funções institucionais do Ministério Público:

I- (...);

II-(...); 
III - promover o inquérito civil e a ação civil pública, para a proteção do patrimônio público e social, do meio ambiente e de outros interesses difusos e coletivos;

(...).

Meirelles (2008, p. 591) explica que a ação civil pública suspende liminarmente a conduta poluidora, impondo ao réu a obrigação de fazer ou de se abster do fato prejudicial ao meio ambiente.

A Lei 9.605/98 regulamenta a proteção ambiental, dispondo de normas sobre as sanções penais e administrativas lesivas ao meio ambiente, elencados em crimes contra a fauna, a flora, a administração ambiental, o ordenamento urbano, o patrimônio cultural e crimes contra o meio ambiente em geral.

A proteção ambiental é de extrema importância, para que sejam atendidas as necessidades da sociedade, proporcionando o bem-estar, e um futuro saudável para as futuras gerações. A natureza é a base de tudo, sem ela não há vida, portanto, sua preservação é fundamental para a humanidade, para o planeta Terra em sua complexidade total.

Wolff explica que:

A variável ambiental perpassa o Estatuto da Cidade, mas o "matiz verde" que se pretende aqui ressaltar é aquele da esperança, que não será vã se houver mudança efetiva de comportamento de cada um em relação ao seu meio. O novo ambiente urbano que se propõe, é aquele "construível" a partir de atitudes mais justas, solidárias, democráticas, e, a Lei no 10.257 de 2001, instrumento de excelência para essa transmutação, coloca meios fundamentais à disposição do cidadão para que este busque a satisfação de suas necessidades urbanas fundamentais, mas também ecológicas, sociais, culturais, econômicas (WOLFF, 2003, p. 9).

Ainda, expõe Tórtola que:

Não há como dissociar o cumprimento da função social da propriedade e a preservação ambiental, uma vez que o primeiro decorre logicamente do segundo. E também não se pode dizer que exista um conflito entre o direito de propriedade e a proteção jurídica do meio ambiente. Os direitos de propriedade e do meio ambiente salubre devem ser compatibilizados (TÓRTOLA, 2012, p. 155).

Contudo, a cidade deve ser planejada, prevalecendo-se harmonicamente nela os direitos sociais, econômicos, fundamentais e ambientais, desenvolvendo-se um ambiente urbano sustentável em que prevaleça a dignidade da pessoa humana e a liberdade individual. 
Além disso, para que a cidade exerça suas funções, Maciel e Schorr destacam que é muito importante:

Implantar uma gestão democrática nas cidades, com participação dos cidadãos na tomada de decisões é fator preponderante e imprescindível na luta pela efetivação das funções sociais da cidade, que poderá gerar melhores condições de vida aos citadinos, respeitando os princípios da dignidade humana e da cidadania, entendida como a garantia dos direitos e deveres de todos os cidadãos independente das condições em que se encontrem. É fundamental que a discriminação e as desigualdades sociais sejam reduzidas para que sejam efetivados os direitos humanos (MACIEL; SCHORR, 2015, p. 160).

Tórtola (2012, p. 161) conclui que "o desenvolvimento sustentável propõe que o crescimento socioeconômico caminhe no mesmo passo que a preservação ambiental e, para tanto, o Poder Público deve promover políticas públicas para imposição destes direitos".

O Estatuto da Cidade elenca alguns instrumentos para promover o Planejamento Urbano adequado e conforme exposto, destaca-se dentre eles o Plano Diretor.

Assim, passa-se a análise das diretrizes deste instrumento, como uma importante e eficaz medida para consecução do ideal planejamento urbano, devido a que suas exigências buscam assegurar o desenvolvimento sustentável, promovendo a democracia com participação popular na tomada de decisões, o que proporciona uma melhora no atendimento das necessidades dos cidadãos quanto à qualidade de vida, à justiça social e ao desenvolvimento das atividades econômicas.

\section{PLANO DIRETOR COMO POLÍTICA PÚBLICA PARA A PROMOÇÃO DO ESTADO SOCIOAMBIENTAL DE DIREITO}

Como exposto, todos os cidadãos têm direito à cidade, que é entendido como o direito à moradia digna, a terra urbanizada, ao saneamento ambiental, ao trânsito seguro, à mobilidade urbana, à infra-estrutura e aos serviços e equipamentos urbanos de qualidade, além de meios de geração de renda e acesso à educação, saúde, informação, cultura, esporte, lazer, segurança pública, trabalho e participação (MINISTÉRIO DAS CIDADES, 2004, p. 77). Para que a cidade atinja seu fim, deve dispor de normas impositoras capazes de promover a reforma urbana, visando o bem comum da coletividade. 
Conforme exposto por Wolff:

O Estatuto da Cidade teve a proposta inédita de agregar valores impregnados de justiça, democracia e solidariedade, inserindo-se em um contexto de barreira à imobilidade e à inércia, representando um marco fundamental de conscientização e mudanças de comportamento a médio e a longo prazos à disposição de todo cidadão brasileiro. Aliando a busca permanente do desenvolvimento urbano em bases sustentáveis ao esforço contínuo de instauração da justiça social e ambiental nas cidades, o Estatuto opõe-se à destruição do ambiente e ao aviltamento do homem, o que representa um imenso desafio para o País e suas instituições (WOLFF, 2003, p. 9).

O Estatuto da Cidade definiu o Plano Diretor como sendo o instrumento básico para a política de desenvolvimento e expansão urbana.

Hely Lopes Meirelles conceituou:

O Plano Diretor ou Plano Diretor de Desenvolvimento Integrado, como modernamente se diz, é o complexo de normas legais e diretrizes técnicas para o desenvolvimento global, constante do Município, sob os aspectos físico, social, econômico e administrativo, desejado pela comunidade local. Deve ser a expressão das aspirações dos munícipes quanto ao progresso do território municipal no seu conjunto cidade/campo. É o instrumento técnico-legal definido dos objetivos de cada Municipalidade e por isso mesmo com supremacia sobre os outros, para orientar toda atividade de Administração e dos Administrados nas realizações públicas e particulares que interessem ou afetem a coletividade. O Plano Diretor deve ser uno e único, embora sucessivamente adaptado às novas exigências da comunidade e do progresso local, num processo perene de planejamento que realize sua adequação às necessidades da população, dentro das modernas técnicas de administração e dos recursos de cada Prefeitura. 0 Plano Diretor não é estático; é dinâmico e evolutivo. Na fixação dos objetivos e na orientação do desenvolvimento do Município é a lei suprema e geral que estabelece as prioridades nas realizações do governo local, conduz e ordena o crescimento da cidade, disciplina e controla as atividades urbanísticas em benefício do bem-estar social (MEIRELLES, 2006, p. 549 e 550).

O Plano Diretor é uma alternativa para as cidades que enfrentam a expansão horizontal ilimitada, avançando sobre áreas frágeis ou de preservação ambiental. É o instrumento básico para promover o bom desenvolvimento do Município, tendo como escopo orientar a atuação do poder público e da iniciativa privada na construção dos espaços urbano e rural, visando assegurar melhores condições de vida para a população.

Este instrumento busca atender as necessidades da sociedade no âmbito da cidade, seguindo diretrizes básicas de planejamento urbano para que haja um uso adequado do solo, onde se preserve a função social da cidade e da propriedade, contando principalmente com a participação popular, 
juntamente com a Administração Municipal. Ele vem organizar a cidade, proteger o direito dos cidadãos sobre ela, aplicar medidas de prevenção contra irregularidades privadas, melhorar o desenvolvimento, a distribuição de renda, garantir a moradia digna, o saneamento básico, a iluminação pública, a educação e o transporte público.

De acordo com as diretrizes expressas no Estatuto da Cidade, os Planos Diretores devem contar necessariamente com a participação da população e de associações representativas dos vários segmentos econômicos, sociais e culturais durante todo o seu processo de elaboração, tornando-se um espaço de debate entre os cidadãos de definição das opções. O desafio lançado pelo Estatuto incorpora o que existe de mais vivo e vibrante no desenvolvimento da nossa democracia - a participação direta (e universal) dos cidadãos nos processos decisórios (SAULE JUNIOR, 2001).

Destaque-se a prevalência democrática no seu processo de implementação. Este fator é muito importante, no sentido de que onde há a participação do povo há a cidadania, a liberdade, a justiça.

Carvalho Júnior e Silva (2017, p. 69) destacam que "encontrar mecanismos de participação popular significa congregar na vida política e decisória do Estado, espaço para a representação, espaço para a técnica e gestão, mas também espaço para o cidadão que pode e deve se preocupar com as coisas públicas".

Neste diapasão, o Plano Diretor é um importante instrumento que garante a participação do povo na tomada de decisões sobre o parcelamento do solo urbano de seu município, ascendendo à cidadania, atendendo aos princípios de sustentabilidade.

O Plano Diretor, portanto, pode ser considerado como a manifestação mais latente da gestão democrática da cidade, que se coaduna com o princípio da soberania popular, previsto no art. 1으, parágrafo único da Carta Magna de 1.988. Ele deve abranger todo o Município, reconhecendo a integralidade do território, observando as peculiaridades de cada região da cidade. O solo urbano deve ser, para tanto, pensado como uma zona intermitente de conflitos, porque a cidade é um campo de contradições, onde cada indivíduo busca o seu bem estar, e não o da comunidade, e o planejamento urbano é essencial no sentido de mudar este pensamento humano, planejando a cidade para que se reduzam a discriminação e as desigualdades sociais, efetivando-se os direitos humanos e prevalecendo toda a comunidade.

A Constituição Federal ainda dispõe em seu artigo 182, que o Plano Diretor é obrigatório para as cidades com mais de vinte mil habitantes e que deve ser o instrumento básico da política de desenvolvimento urbano, delegando ao Município a competência para executá-lo, por deter a função 
de conduzir ordenadamente o desenvolvimento das funções sociais da cidade e garantir o bem-estar de seus habitantes.

No processo de elaboração do Plano Diretor devem prevalecer o princípio da publicidade e a participação popular, obedecendo às normas estabelecidas pelo artigo 40, § 40 da Lei 10.257/01, que regulamenta o Estatuto da Cidade.

Diante do exposto, para que haja eficácia na aplicação do planejamento urbano é importante e necessária a conscientização da população, pois, um particular deverá se desfazer de alguns direitos para que todos sejam beneficiados. Isto gera um entrave na hora da aplicação das normas técnicas, pelo fato de ser o homem um ser de "natureza egoísta", capaz de pensar apenas em si mesmo, atrapalhando o bom desenvolvimento das relações na cidade. Podemos observar isto quanto à distribuição de renda, as divisões de classes sociais, fatores que causam desigualdades na população.

Freitag (2010) apud Maciel e Schorr:

Há um contraste evidente! De um lado, em razão da globalização, temos áreas urbanas embasadas no consumismo, com carros particulares, e muitas vezes em número de um para cada integrante da família, condomínios em bairros nobres e compras em shoppings. Por outro, há grande parte de excluídos que vivem em favelas ilegais, sem trabalho, saúde, espaço legalizado e, muitas vezes, sem possuir ao menos o registro civil que os garanta o status de cidadão (MACIEL; SCHORR, 2015, p. 157).

Maciel e Schorr (2015, p. 157) destacam que o direito à cidade não é apenas o acesso à cidade, e sim o direito a transformar a cidade em um espaço democrático, um ambiente onde não haja segregação e sim a participação de todos, onde o agir coletivamente aconteça, onde a diferença apareça, mas acrescente e não separe, onde a alteridade esteja presente, não como um fator que aparta, mas que une.

A maioria dos autores defende que o alcance da sociedade sustentável está amparado na democracia, por ser uma forma de governo que tem como pressupostos a igualdade e participação social na tomada de decisões.

Corroboram neste sentido Maciel e Schorr que:

A conciliação entre desenvolvimento e meio ambiente deve ser realizada por meio da exploração equilibrada dos recursos naturais, que visem o bem-estar da geração atual, sem esquecer, também, das futuras gerações. $O$ crescimento econômico deve buscar uma equitativa redistribuição do processo produtivo, bem como a erradicação da pobreza, como forma de reduzir as diferenças entre padrões de vida e, consequentemente, a pobreza absoluta; além de levar em 
consideração o equilíbrio entre viabilidade econômica e viabilidade ecológica. Nisto encontra-se a utilização das dimensões do ecodesenvolvimento. [...] O que se quer, com isto, é que efetivamente se exerça a democracia e a cidadania, havendo uma maior participação daquele que é, ou deveria ser, realmente o destinatário das normas e diretrizes, qual seja, o povo. Quando se democratiza a democracia através da participação, se busca a melhoria da qualidade da atuação dos cidadãos nas decisões que envolvem a coletividade (MACIEL; SCHORR, 2015, p. 158).

Com o advento da Constituição Federal de 1988, o poder governamental se descentralizou, aumentando a autonomia e independência das gestões locais, reforçando que o plano diretor é o instrumento principal do planejamento urbano, e preconizando a gestão democrática em todas as suas etapas (OLIVEIRA et al., 2015, p. 5).

É por meio do planejamento participativo que a população poderá compartilhar a responsabilidade nas decisões e, ainda, ter garantido o direito de se manifestar sobre as grandes questões de sua cidade (PONTES; FARIA, 2012, p. 96).

O artigo 43, previsto no capítulo IV do Estatuto da Cidade, indica quatro instrumentos para garantir a gestão democrática, que são exigidos para que os planos diretores tenham efetiva participação popular e eficácia na sua implementação, quais sejam: os órgãos colegiados de política urbana nos níveis nacional, estadual e municipal; debates, audiências e consultas públicas; conferências sobre assuntos de interesse urbano nos níveis nacional, estadual e municipal; e iniciativa popular de projeto de lei e de planos, programas e projetos de desenvolvimento urbano.

Os órgãos colegiados de política urbana, nos níveis nacional, estadual e municipal, mais conhecidos como Conselhos, se encontram no inciso I, do artigo 43, do Estatuto da Cidade, de extrema relevância por promover um espaço de ligação entre o poder público e a sociedade, podendo ter papel deliberativo e/ou consultivo sobre os anseios da cidade.

Os debates, audiências e consultas Públicas são os mecanismos mais utilizados tanto na Construção como na Atualização dos Planos Diretores e, ganham destaque por proporcionar a concretização de princípios constitucionais que se relacionam com institutos participativos, evidenciando o da prestação de informações de interesse geral, que encontra previsão tanto no artigo 5o, XXXIII como no artigo 37, pelo princípio da publicidade; os princípios do devido processo legal (artigo 5ㅇ, LIV, CF) e o da ampla defesa (artigo 5ㅇ, LV, CF); e, o controle por via de ação popular (artigo 5ㅇ, LXXIII, CF).

Aqui, alerta Silva (2006, p. 9), para uma via em que os cidadãos devem se tornar corresponsáveis pelas políticas públicas urbanas, explicando que devemos "conjugar os debates, 
audiências e consultas públicas a todo um processo de formação e de acesso à informação", eis que, "investir em participação é possibilitar o exercício da autonomia, na independência do pensar e do agir".

Já as conferências sobre assuntos de interesse urbano tratadas no inciso III do artigo 43 do Estatuto da Cidade, embora não possuam expressa previsão constitucional no âmbito urbanístico, vem demonstrando grande eficácia pela promoção da participação de vários setores nos processos de desenvolvimento urbano, entendendo que "as conferências devem ser vistas mais como foros para a formação de uma cultura de participação popular e consulta democrática na formulação de políticas, do que propriamente como um expediente legal vinculante" (BUCCl, 2002, p. 349).

Quanto à iniciativa popular, o Estatuto da Cidade tratou de reaver este instrumento com vistas a projeto de leis e de planos, programas e projetos de desenvolvimento urbano, proporcionando para que "a própria sociedade pode, diante da inércia do Legislativo local, propor a apreciação de projetos que tenham por objeto a formalização destes instrumentos" (SILVA, 2006, p. 12), caracterizando, portanto, um grande avanço na participação.

Sendo assim, o Plano Diretor se destaca dentre os instrumentos de política de desenvolvimento e expansão urbana por em seus processos de elaboração e atualização, ser obrigatória a utilização destes mecanismos de gestão democrática tratados pelo Estatuto da Cidade, que são importantes espaços participativos destinados a cunhar efetividade aos projetos urbanísticos, por favorecerem a organização popular em busca de melhores condições de vida para os habitantes da cidade.

Os processos de elaboração e atualização do Plano Diretor devem, necessariamente, contar com a presença de um Conselho da Cidade, que conterá membros de todos os setores, como: técnicos e especialistas, funcionários públicos, autoridades, representantes dos bairros, dentre outros, além disso, deverão ocorrer audiências públicas para se discutir as necessidades da população e Consultas Públicas em busca de propostas de melhoria para os assuntos que devem ser tratados pelo Plano, fatores que tornam um instrumento de relevante importância democrática.

Portanto, para que seja desenvolvida uma política urbana que garanta melhores condições de vida para a população, uma cidade sustentável, é necessário que se desenvolva uma cultura de gestão participativa do cidadão, exercício da democracia e, por suas diretrizes, o Plano Diretor, se devidamente implementado, se torna um instrumento eficaz de garantia deste Estado Socioambiental de Direito. Por meio dele serão garantidos os direitos fundamentais da pessoa humana, com a participação ativa do cidadão na comunidade. 


\section{CONSIDERAÇÕES FINAIS}

As cidades brasileiras vivenciam cada vez mais situações degradantes no que tange aos problemas urbanos, causados em grande parte pela rápida ocupação e falta de planejamento urbano.

Este crescimento acelerado da população, que se deu de forma desordenada, sem o devido planejamento, plasmou grandes desafios de sustentabilidade, muitas das vezes por fatores de omissão do poder público e falta de interesse da população na fiscalização das decisões, acarretando inúmeras consequências socioambientais, como desigualdades sociais, inundações e desmoronamentos, geralmente, atingindo a população de baixa renda, que normalmente é alocada nas periferias das cidades, em áreas carentes de infraestrutura.

Assim, o solo urbano é pensado como uma zona intermitente de conflitos, porque a cidade é um campo de contradições, onde cada indivíduo busca o seu bem estar, e não o da comunidade.

Com tudo, a legislação tratou o planejamento urbano como fator modificativo desta premissa, convertendo para que o ordenamento da cidade busque a redução da discriminação e das desigualdades sociais, buscando a efetividade dos direitos humanos para que se prevaleça o interesse comum sobre o particular.

O Direito Urbanístico então, nasceu como um meio de remediar esse cenário, que passou por uma grande evolução no Brasil nas últimas décadas. A Constituição Federal de 1988 e o Estatuto da Cidade se destacam como importantes marcos, em termos de legislação urbana, por consagrarem princípios e instrumentos importantes para o desenvolvimento urbano tão almejado pela sociedade brasileira.

Saliente-se que no processo de desenvolvimento das cidades, é necessário que se atenda aos princípios de direito urbanístico, principalmente o princípio da função social da propriedade urbana que tem como embasamento fazer prevalecer o interesse social, o meio ambiente equilibrado e a dignidade.

E, o Plano Diretor se coloca como um importante instrumento de gestão democrática urbana para garantir a concreção destes direitos, instituidor da cidadania e democracia, tendo em suas diretrizes normas quanto ao direito de propriedade, que efetivam os princípios de direito urbanístico, capazes de proporcionar melhores condições de vida e dignidade à população, tratando em sua norma de regularizar questões cruciais como a moradia e expansão urbana, diminuindo as desigualdades sociais, evitando problemas como favelização, empobrecimento de parcela da população, miséria e 
delinquência, em razão da má-distribuição de renda, da especulação imobiliária e da ausência de reforma agrária, preocupando-se com o meio ambiente e com o desenvolvimento da cidade.

O Plano Diretor exerce um papel muito importante nos municípios, definindo as diretrizes básicas para promover a política urbana, o uso adequado do solo, além de ser instrumento garantidor da cidadania, com a participação popular obrigatória na construção de suas diretrizes. Aos cidadãos são concedidos espaços participativos de interlocução com o poder público a fim de garantir a efetividades dos preceitos do Plano Diretor.

Destarte, o Plano Diretor é um forte instrumento na promoção do desenvolvimento sustentável das cidades, sendo plenamente capaz de promover a superação das desigualdades sociais, sendo imprescindível que haja a implantação de uma gestão democrática nas cidades com a participação popular na tomada de decisões, para promoção de políticas públicas efetivas ao cumprimento de um planejamento urbano, a fim de promover a ordenação do território, o desenvolvimento sustentável, uma política habitacional que assegure o direito social da moradia, a justa distribuição de infraestrutura e serviços urbanos, respeitando os princípios da dignidade humana e da cidadania, cumprindo a função social da cidade, configurando realmente o Estado Socioambiental de Direito.

\section{NOTAS}

1 Art. 182. A política de desenvolvimento urbano, executada pelo Poder Público municipal, conforme diretrizes gerais fixadas em lei, tem por objetivo ordenar o pleno desenvolvimento das funções sociais da cidade e garantir o bem- estar de seus habitantes. (Vide Lei no 13.311, de 11 de julho de 2016)

$\S 1$ O O plano diretor, aprovado pela Câmara Municipal, obrigatório para cidades com mais de vinte mil habitantes, é o instrumento básico da política de desenvolvimento e de expansão urbana.

§ 2 ㅇ A propriedade urbana cumpre sua função social quando atende às exigências fundamentais de ordenação da cidade expressas no plano diretor.

§ 3으 As desapropriações de imóveis urbanos serão feitas com prévia e justa indenização em dinheiro.

§ 4ㅇ É facultado ao Poder Público municipal, mediante lei específica para área incluída no plano diretor, exigir, nos termos da lei federal, do proprietário do solo urbano não edificado, subutilizado ou não utilizado, que promova seu adequado aproveitamento, sob pena, sucessivamente, de:

I - parcelamento ou edificação compulsórios;

II - imposto sobre a propriedade predial e territorial urbana progressivo no tempo;

III - desapropriação com pagamento mediante títulos da dívida pública de emissão previamente aprovada pelo Senado Federal, com prazo de resgate de até dez anos, em parcelas anuais, iguais e sucessivas, assegurados o valor real da indenização e os juros legais.

2 Art. 183. Aquele que possuir como sua área urbana de até duzentos e cinquenta metros quadrados, por cinco anos, ininterruptamente e sem oposição, utilizando-a para sua moradia ou de sua família, adquirir-lhe-á o domínio, desde que não seja proprietário de outro imóvel urbano ou rural.

$\S 1$ o O título de domínio e a concessão de uso serão conferidos ao homem ou à mulher, ou a ambos, independentemente do estado civil. 
§ 2을 Esse direito não será reconhecido ao mesmo possuidor mais de uma vez.

$\S 3$ ○o Os imóveis públicos não serão adquiridos por usucapião.

\section{REFERÊNCIAS}

BOBBIO, Norberto. A era dos direitos. Trad. Carlos Nelson Coutinho. Rio de Janeiro: Campus, 1992.

BRASIL. Constituição da República Federativa do Brasil de 1988. Disponível em <

http://www.trtsp.jus.br/legislacao/constituicao-federal-emendas>. Acesso em 05 jul. 2017.

BRASIL. Lei 10.257, DE jul. 2001. Estatuto da Cidade. Brasília-DF, jul. 2001. Disponível em < http://www.planalto.gov.br/ccivil_03/leis/LEIS_2001/L10257.htm> Acesso em: out. 2018.

BRASIL. Lei 10.406, de jan. 2002. Código Civil. Brasília - DF, jan. 2002. Disponível em< http://www.planalto.gov.br/ccivil_03/LEIS/2002/L10406.htm>. Acesso em 01 março 2019.

BRASIL. Lei 9.605, de 12 de fevereiro de 1998. Sanções Penais e Administrativas Derivadas de Condutas e Atividades Lesivas ao Meio Ambiente, e dá outras providências. Brasília-DF, fev 1.998. Disponível em <http://www.planalto.gov.br/ccivil_03/leis/L9605.htm>. Acesso em 26 fev. 2019.

BUCCI, Maria Paula Dallari. Gestão democrática da cidade. In: DALLARI, Adilson Abreu \& FERRAZ, Sérgio. (coords). Estatuto da Cidade (comentários à Lei Federal 10.257/2001). São Paulo: Malheiros, 2002.

CASTELLS, Manuel. A Questão urbana. 3. ed. Rio de Janeiro: Paz e Terra, 1983.

COELHO, Nuno Manuel Morgadinho dos Santos; OLIVEIRA, Rafael Tomaz de. Dignidade humana em perspectiva política: Charles Taylor e a reabilitação das questões ontológicas no campo da política. Revista Direito, Estado e Sociedade. Pontifícia Universidade Católica do Rio de Janeiro. no 53, julho/dezembro 2018. Disponível em <http://direitoestadosociedade.jur.pucrio.br/cgi/cgilua.exe/sys/start.htm ?infoid=385\&sid=36\&tpl=printerview $>$. Acesso em 5 agosto 2019.

DINIZ, Maria Helena. Código Civil Anotado. 14a ed. Saraiva, 2009.

GONÇALVES, Carlos Roberto. Direito Civil Brasileiro. Volume V - Direito das Coisas. 12a ed. São Paulo: Saraiva, 2017.

HARADA, Kyoshi. Desapropriação - Doutrina e prática. 6. ed. São Paulo: Atlas, 2006.

HUMBERT, Georges Louis Hage. Princípios constitucionais informadores do direito urbanístico. Jus Navigandi, set. 2006. Disponível em: < http://www.egov.ufsc.br/portal/sites/default/files/anexos/29788-29804-1-PB.pdf>. Acesso em: 04 março 2019.

LEHFELD, Lucas de Souza; OLIVEIRA, Raul Miguel Freitas; ESTADO SOCIOAMBIENTAL DE DIREITO E O CONSTITUCIONALISMO GARANTISTA. o princípio in dubio pro natura como mecanismo de controle do ativismo judicial contrário à tutela dos direitos fundamentais ambientais. Maio. 2016. Disponível em: < https://www.conpedi.org.br/publicacoes/c50o2gn1/212559so/JUORPBaakN1ZQ94c.pdf>.

Acesso em: 01 março 2019. 
MACIEL, Renata; SCHORR, Janaína Soares; O DIREITO A POSSUIR UM ESPAÇO URBANO E A (IN)EFICÁCIA DO ESTADO: UMA ANÁLISE DO CONTEXTO ATUAL BRASILEIRO. 2015. Disponível em: < http://revistas.unaerp.br/paradigma/article/view/491/541>. Acesso em 24 março 2020.

MEIRELLES, Hely Lopes. Direito municipal brasileiro. Malheiros. 13. ed. São Paulo: 2006.

MEIRELLES, Hely Lopes. Direito Municipal Brasileiro. 16. ed. São Paulo: Malheiros, 2008.

MINISTÉRIO DAS CIDADES. Política Nacional de Desenvolvimento Urbano 1. Novembro, 2004. Disponível em: < https://erminiamaricato.files.wordpress.com/2012/03/cadernos-mcidadespolc3adtica-nacional-de-desenvolvimento-urbano.pdf> Acesso em 24 março 2020.

MUKAI, Toshio. Direito urbano-ambiental brasileiro. 2. ed. rev. e ampl. São Paulo: Dialética, 2002.

MUKAI, Toshio. Temas atuais de direito urbanístico e ambiental. 1. ed. Belo Horizonte: Editora Fórum, 2007.

NASCIMENTO, Rafael Rodrigues. O Direito ao Meio Ambiente Ecologicamente Equilibrado. Disponível em:

<https://www.univates.br/graduacao/media/direito/o_direito_ao_meio_ambiente_ecologicamente _equilibrado.pdf>. Acesso em 01 março 2019.

OLIVEIRA, Celso Maran de; LOPES, Dulce; SOUSA, Isabel Cristina Nunes de. Direito à participação nas políticas urbanísticas: avanços após 15 anos de estatuto da cidade. urbe, Rev. Bras. Gest.

Urbana, Curitiba, v. 10, n. 2, p. 322-334, Ago. 2018. Disponível em:

$<$ http://www.scielo.br/scielo.php?script=sci_arttext\&pid=S2175-

33692018000200322\&Ing=en\&nrm=iso>. Acesso em: 16 mar. 2021.

PASSOS, J. J. Calmon. Cidadania tutelada. In: FERREIRA, Luiz Alexandre Cruz. Hermenêutica, Cidadania e Direito. Campinas-SP: Millennium, 2005.

PONTES, Daniele Regina; FARIA, José Ricardo Vargas de. Direito municipal e urbanístico. ed. rev. Curitiba, PR: IESDE, 2012.

SARLET, I. W.; FENSTERSEIFER, T. Direito Constitucional Ambiental: Constituição, direitos fundamentais e proteção do ambiente. 2 ed. rev. e atual. São Paulo: RT, 2012.

SAULE JUNIOR. Nelson. Direito à cidade: trilhas legais para o direito às cidades sustentáveis. São Paulo: Max Limonad, 1999.

SILVA, Márcio Luiz da. A Gestão democrática municipal diante das possibilidades e restrições trazidas pelo estatuto da cidade e pelo plano diretor. Congresso Nacional do CONPEDI (14.: 2005 : Fortaleza, CE) Anais do / XIV Congresso Nacional do CONPEDI. - Florianópolis: Fundação Boiteux, 2006. Disponível em:

<http://www.publicadireito.com.br/conpedi/manaus/arquivos/anais/XIVCongresso/146.pdf >. Acesso em: 16 mar. 2021.

SILVA, Juvêncio Borges; JÚNIOR, Natal dos Reis Carvalho. DEMOCRATIZAR A DEMOCRACIA: participação popular como meio de superação dos obstáculos a consolidação democrática no Brasil. 
Revista Húmus. V.7, n. 20, 2017. Disponível em:

http://www.periodicoseletronicos.ufma.br/index.php/revistahumus/article/view/6786/4844. Acesso em 01 março 2019.

TÓRTOLA, Elissandra Roberta. 0 direito de propriedade em face da preservação ambiental. Revista Jurídica da Escola Superior do Ministério Público de São Paulo, v. 1, 2012. Disponível em:

http://www.esmp.sp.gov.br/revista_esmp/index.php/RJESMPSP/article/viewFile/22/11. Acesso em: 01 março 2019.

WOLFF, Simone. Estatuto da Cidade: A Construção da Sustentabilidade..., Revista Jurídica Virtual Brasília, vol. 4, n. 45, fev. 2003. Disponível em https://revistajuridica.presidencia.gov.br/index.php/saj/article/view/754/745. Acesso em 26 fev 2019.

Trabalho recebido em 20 de abril de 2020

Aceito em 19 de março de 2021 